\title{
Neuroleptic induced parkinsonism: MRI findings in relation to clinical course after withdrawal of neuroleptic drugs
}

\author{
V Bocola, G Fabbrini, A Sollecito, C Paladini, N Martucci
}

Casa di Cura Villa Pini D'Abruzzo', Chieti, Italy

V Bocola

A Sollecito

C Paladini

Department of

Neurosciences,

University La

Sapienza, Rome, Italy

G Fabbrini

Istituto

Neurotraumatologico

Italiano, Grottaferrata

Rome, Italy

N Martucci

Correspondence to:

Dr Giovanni Fabbrini,

Department of

Neurosciences, University

"La Sapienza", Viale

"La Sapienza", Viale

Rome, Italy.

Received 9 February 1995

and in revised form

5 October 1995

Accepted 5 October 1995

\begin{abstract}
Parkinsonism is a common complication of neuroleptic drug use; however, the pathophysiology of the persistence of parkinsonian symptoms after withdrawal of neuroleptic drugs is poorly understood. Twenty patients with neuroleptic induced parkinsonism were studied by high field MRI. Persistence of symptoms was associated with different findings depending on the age of the patients-namely, putaminal hypointensity in young patients and striatal hyperintensities in old patients. High field MRI may be useful in identifying patients at higher risk for neuroleptic induced parkinsonism.
\end{abstract}

$(尹$ Neurol Neurosurg Psychiatry 1996;60:213-216)

Keywords: magnetic resonance imaging; parkinsonism; neuroleptic drugs

The clinical course of neuroleptic induced parkinsonism after withdrawal of neuroleptic drugs may be characterised by rapid remission of symptoms (within five to 60 days), by persistence of symptoms, or by further progressive deterioration. ${ }^{1-6}$ Whereas it is generally agreed that the extrapyramidal symptoms are linked to the functional blockade of postsynaptic dopaminergic receptors, several mechanisms have been suggested to explain the pathophysiology of progressive or persistent forms. Studies using PET have shown a high degree of correlation between persistence or progression of symptoms and low putaminal uptake of ${ }^{18} \mathrm{~F}$-dopa. ${ }^{7}$ Genetic factors, ${ }^{8}$ toxicity of neuroleptic drugs beyond dopaminergic

Table 1 Demographic and clinical characteristics of patients with neuroleptic induced parkinsonism (NIP)

\begin{tabular}{lcc}
\hline & $\begin{array}{l}\text { Young NIP }(n=10) \\
(\text { mean }(S D))\end{array}$ & $\begin{array}{l}\text { Old NIP }(n=10) \\
(\text { mean }(S D))\end{array}$ \\
\hline Age (y) & $34 \cdot 6(6 \cdot 9)$ & $65 \cdot 6(3 \cdot 9)$ \\
Education (y) & $13 \cdot 7(3 \cdot 4)$ & $5 \cdot 0(4 \cdot 0)$ \\
MMSE & $25 \cdot 6(5 \cdot 8)$ & $22(7 \cdot 1)$ \\
Symptom duration (y) & $9 \cdot 8(6 \cdot 6)$ & $28(4 \cdot 2)$ \\
Neuroleptic treatment (y) & $7 \cdot 1(5 \cdot 1)$ & $15(6 \cdot 3)$ \\
Neuroleptic dose & $330(97 \cdot 7)$ & $170(74 \cdot 4)$ \\
(mg eq chlorpromazine) & $10(100 \%)$ & $5(50 \%)$ \\
Anticholinergic drugs & 0 & $4(40 \%)$ \\
Other treatments & & \\
\hline
\end{tabular}

blockade, ${ }^{9}$ and acceleration of idiopathic Parkinson's disease ${ }^{10}$ have all been postulated. Functional age related changes in dopamine receptors and striatal concentrations of dopamine may play an important part. An MRI study has shown a high prevalence of focal hyperintensities in the caudate nucleus of aging patients with neuroleptic induced parkinsonism with respect to age matched

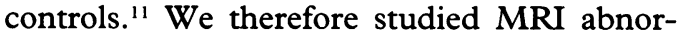
malities in young and old patients with neuroleptic induced parkinsonism in relation to their clinical course after neuroleptic withdrawal.

\section{Patients and methods}

Twenty patients with a diagnosis of "chronic schizophrenic disturbance" (DSM-III) chronically treated with neuroleptic drugs consented to participate in this study. Patients were selected from about 100 inpatients admitted to the psychiatric facilities of Villa Pini (Chieti, Italy). Patients were subdivided into two groups based on their age. The first consisted of 10 patients with an age range of 18-45 years, and the second of 10 patients older than 60 . Patients were selected only when there was no clear contraindication to the withdrawal of neuroleptic drugs in terms of behavioural disturbances and compliance with instructions, and when misuse of alcohol or other drugs could be excluded. Patients with a mini mental state examination score of less than 17 were also excluded. Table 1 describes the demographic and clinical characteristics of the two groups.

Patients were evaluated at baseline $\left(t_{0}\right)$ for severity of extrapyramidal symptoms with a shortened version of the unified Parkinson's disease rating scale (UPDRS) ${ }^{12}$ which considers six cardinal symptoms (bradykinesia, rigidity, tremor, postural instability, gait, posture) each scored on a scale from 0 (absent) to 4 (severe), with a total maximum score of 24 . The presence of other movement disorders was evaluated by means of the abnormal involuntary movements rating scale (AIMS).

MRI studies were performed on all patients using a superconducting magnet (Magneton Siemens) operating at 1.5 Tesla, with $\mathrm{T} 1$ $(\mathrm{TR} / \mathrm{TE}=500 / 15 \mathrm{~ms})$ and $\mathrm{T} 2 \quad(\mathrm{TR} / \mathrm{TE}=$ $2000 / 90 \mathrm{~ms}$ ) weighted sagittal, coronal, and 
Table 2 Changes in UPDRS scores after neuroleptic drug withdrawal

\begin{tabular}{|c|c|c|}
\hline & $t_{0}$ & $t_{l}$ \\
\hline $\begin{array}{l}\text { Young patients with } \operatorname{NIP}(n=10) \\
\text { Old patients with } \operatorname{NIP}(n=10)\end{array}$ & $\begin{array}{r}11 \cdot 8(2 \cdot 3) \\
8 \cdot 6(2 \cdot 6)\end{array}$ & $\begin{array}{l}5 \cdot 3(5 \cdot 1)^{\star \star} \\
7 \cdot 1(2 \cdot 4)^{\star}\end{array}$ \\
\hline
\end{tabular}

axial planes and a slice thickness of $5 \mathrm{~mm}$. Images were analysed by a radiologist blind to the purpose of the study for the presence or absence of focal signal alterations, white matter abnormalities, cortical or subcortical atrophy, or other signal alterations. Putaminal hypointensity was defined as the intensity which was equal or less than that of the globus pallidus. Areas of relative comparison were chosen on constant regions of interest $(0.2$ pixels) localised on the tail of the putamen and on the corpus of the globus pallidus.

Neuroleptic drugs were then slowly tapered over three successive weeks to complete withdrawal; weekly visits allowed us to recognise the reappearance of psychotic symptoms and to treat these eventually with clozapine; motor symptoms were checked monthly; the final visit was scheduled six months $\left(t_{1}\right)$ after neuroleptic withdrawal.

Statistical analysis was performed by Wilcoxon sum ranking test (within group between $t_{0}$ and $t_{1}$ ) and with a Mann-Whitney $U$ test (between groups). Correlation between variables was calculated by Spearman's test.

\section{Results}

Clinical presentation differed between young and old patients with neuroleptic induced parkinsonism. Among the 10 young patients, eight had bradykinesia as the predominant symptom associated with postural tremor or rigidity, and two complained mainly of tremor. None of these patients had vascular risk factors. Among the old patients, eight complained chiefly of tremor (rest tremor in five and postural tremor in three) with associated rigidity in five and bradykinesia in three. Two patients had only a rigid-akinetic syndrome without tremor. In seven patients symptoms were bilateral and symmetric. Three of these patients had high blood pressure and two had

Table 3 MRI findings in old patients with neuroleptic induced parkinsonism in relation to clinical course after withdrawal of neuroleptic drugs

\begin{tabular}{llcc}
\hline & $\begin{array}{l}\text { Rapid remission } \\
\text { of symptoms } \\
(5-60 \text { days) }\end{array}$ & $\begin{array}{l}\text { Slow remission } \\
\text { of symptoms } \\
(>60 \text { days }) \\
(n=5)\end{array}$ & $\begin{array}{l}\text { Persistent } \\
\text { symptoms } \\
(n=5)\end{array}$ \\
\hline $\begin{array}{l}\text { Age } \\
\text { Symptom duration (y) }\end{array}$ & - & $66 \cdot 6(4 \cdot 9)$ & $64 \cdot 6(2 \cdot 8)$ \\
Neuroleptic dose (mg eq & - & $27(5 \cdot 1)$ & $29(3 \cdot 4)$ \\
$\quad$ chlorpromazine) & - & $196(79 \cdot 2)$ & $144(67)$ \\
Baseline UPDRS & $9 \cdot 2(3 \cdot 3)$ & $8 \cdot 0(2 \cdot 0)$ \\
MRI & & 1 & 1 \\
$\quad$ Normal & 4 & 4 \\
$\quad$ Atrophy & 1 & 4 \\
White matter hyperintensities & 0 & 3 \\
$\quad$ Striatal hyperintensities & 1 & 0 \\
\hline Putaminal hypointensity & & & \\
\hline
\end{tabular}

Value are mean $(\mathrm{SD})$ or number of patients.

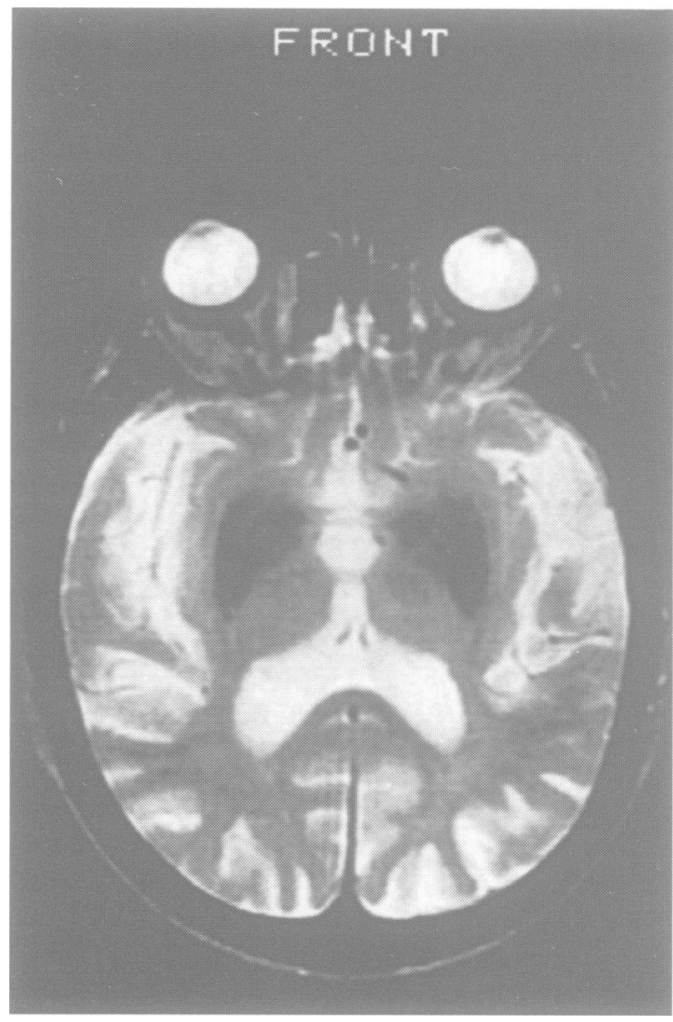

Putaminal hypointensity in a young patient with neuroleptic induced parkinsonism and slow remission of symptoms after withdrawal of neuroleptic drugs.

stable ischaemic cardiopathy. No correlations between UPDRS scores, years of psychiatric symptoms, and dose of neuroleptic drugs were found. None of the young patients exhibited other abnormal movement disorders. On the other hand two old patients had concomitant moderate buccolingual dyskinesiae alone, and two had concomitant mild buccolingual and upper arm dyskinesiae. Brain MRI of these patients was no different from that of the other old patients.

After withdrawal of neuroleptic drugs, mean total UPDRS scores decreased in both groups of patients (table 2). However, the clinical course differed between individual patients. In young patients four had rapid remission of extrapyramidal symptoms, four had slow remission, and two showed persistence of symptoms. In old patients with neuroleptic induced parkinsonism none showed rapid remission, five had a slow remission, and in the remaining five parkinsonian symptoms persisted throughout the follow up. Clozapine was needed in four young patients for reappearance of psychiatric symptomatology. No correlation between pattern of clinical presentation and evolution of parkinsonian symptoms after neuroleptic drug withdrawal was found. In old patients the persistence of parkinsonian symptoms after neuroleptic withdrawal was associated with a high incidence of white matter and striatal hyperintensities in T2 weighted images (table 3 ). In young patients, slow remission and persistence of symptoms were associated with putaminal hypointensity (figure), by contrast with patients showing a rapid and complete remission who had a normal MRI (table 4). 
Table 4 MRI (1.5 tesla T2 weighted) findings in young patients with neuroleptic induced parkinsonism in relation to clinical course after neuroleptic withdrawal

\begin{tabular}{|c|c|c|c|}
\hline & $\begin{array}{l}\text { Rapid remission } \\
\text { of symptoms } \\
\text { (5-60 days) } \\
(n=4)\end{array}$ & $\begin{array}{l}\text { Slow remission } \\
\text { of symptoms } \\
(>60 \text { days }) \\
(n=4)\end{array}$ & $\begin{array}{l}\text { Persistent } \\
\text { symptoms } \\
(n=2)\end{array}$ \\
\hline Age (y) & $31 \cdot 5(6 \cdot 1)$ & $38(5 \cdot 7)$ & $34(14 \cdot 3)$ \\
\hline Symptom duration (y) & $5 \cdot 7(4 \cdot 4)$ & $11 \cdot 2(6 \cdot 2)$ & $15(11 \cdot 3)$ \\
\hline $\begin{array}{l}\text { Neuroleptic dose (mg eq } \\
\text { chlorpromazine) }\end{array}$ & $275(95 \cdot 7)$ & $375(104)$ & $350(70 \cdot 7)$ \\
\hline Baseline UPDRS & $10 \cdot 2(1 \cdot 7)$ & $13(2 \cdot 6)$ & $12 \cdot 5(2 \cdot 1)$ \\
\hline MRI: & & & \\
\hline Normal & 4 & 0 & 1 \\
\hline Atrophy & 0 & 1 & 0 \\
\hline White matter hyperintensities & 0 & 0 & 0 \\
\hline Striatal hyperintensities & 0 & 1 & 1 \\
\hline Putaminal hypointensity & 0 & 3 & 2 \\
\hline
\end{tabular}

Values are mean (SD) or number of patients.

\section{Discussion}

Neuroleptic induced parkinsonism is a common disorder often clinically indistinguishable from idiopathic Parkinson's disease. The onset is within one month of treatment in $50 \%-70 \%$ of patients and within three months in $90 \%$. Mean cumulative incidence is estimated to be $20 \%-50 \%$ of patients treated with neuroleptic drugs. ${ }^{13-15}$ Although the fact that the direct block of dopaminergic receptors is the primary cause for the appearance of parkinsonism is generally accepted, less is known as to why these rapidly wear off in some patients and persist in others. The results of the present study suggest that MRI may be a useful tool in the study of neuroleptic induced parkinsonism, indicating that the susceptibility to develop parkinsonian signs during neuroleptic treatment may have different pathophysiological mechanisms depending on the age of the patients. As expected, old patients had significantly more MRI abnormalities (striatal and white matter hyperintensities) than young patients, and this was more evident in those showing persistence of symptoms. The meaning and clinical relevance of these lesions is still a matter for debate. Previous studies have shown a high degree of correlation with vascular risk factors, dementia, stroke, and aging. Striatal hyperintensities have been variably associated with atherosclerotic parkinsonism ${ }^{16} 17$ and with gait disorders which characterise subcortical arteriosclerotic encephalopathy. ${ }^{18} 19$ Vascular risk factors may therefore clearly have a role in older patients, even though age related changes in striatal dopamine concentrations and receptors may be relevant considering that no patients of this age group showed rapid remission of symptoms.

On the other hand, in younger patients rapid remission of symptoms was seen only in those with normal MRI; in the ones showing an unfavourable clinical course MRI was characterised by the finding of putaminal hypointensity. This finding might be due to a direct toxic effect of neuroleptic drugs. Putaminal hypointensity seems to be correlated with the paramagnetic properties of iron accumulation. An increase in iron concentration is associated with an increased likelihood that oxidative reactions will occur and that free radicals will be produced. ${ }^{20}$ Iron is a transition metal which catalyses oxidative reactions lead- ing to damage of biological molecules and finally to cell degeneration. ${ }^{21}$ Changes in the concentration of transition metals have been implicated in several basal ganglia disorders, including Wilson's disease, Parkinson's disease, multiple systems atrophy, and Hallevorden-Spatz disease. ${ }^{22} 23$ Accumulation of iron with changes in iron metabolism have also been observed in the cortex of patients with Alzheimer's disease, in the white matter of patients with multiple sclerosis or spastic paraplegia. ${ }^{23}$ Neuroleptic drugs may also induce iron accumulation in cerebral tissues, and may modify iron turnover. ${ }^{24}{ }^{25}$ Postmortem studies and $\mathrm{MRI}^{26}{ }^{27}$ have shown an increased accumulation of iron in striatal structures of patients chronically treated with neuroleptic drugs. Increased iron in striatal structures has also been shown in patients with tardive dyskinesiae after prolonged neuroleptic use, ${ }^{28} 29$ a report, however, not confirmed by other authors. ${ }^{30}$

In conclusion, even though the results of this study must be considered as preliminary and need to be confirmed on a larger number of patients, techniques such as MRI may be useful in identifying patients at higher risk for developing neuroleptic induced parkinsonism.

1 Rajput AH, Rozdilsky B, Hornykiewicz O, Shannak K, Lee T, Seeman P. Reversible drug-induced parkinsonism: clinico-pathological study of two cases. Arch Neurol 1982; 39:644-6.

2 Melamed E, Achiron A, Shapira A, Davidovicz S Persistent and progressive parkinsonism after discontinuation of chronic neuroleptic therapy: an additional tardive syndrome? Clin Neuropharmacol 1991;14:273-8.

3 Ayd F. A survey of drug-induced extrapyramidal reactions. ЭAMA 1961;175:1054-60.

4 Klawans HL, Bergen D, Bruyn GW. Prolonged druginduced parkinsonism. Confin Neurol 1973;35:368-77.

5 Crane G. Persistence of neurological symptoms due to neuroleptic drugs. Am f Psychiatry 1971;127:143-6.

6 Aronson AT. Persistent drug induced parkinsonism. Biol Psychiatry 1985;20:795-8.

7 Burn DJ, Brooks DJ. Nygral dysfunction in drug-induced parkinsonism: on ${ }^{18} \mathrm{~F}$-dopa PET study. Neurology 1993; 43:552-6.

8 Myrianthopoulos NC, Waldrop FN, Vincent BL. A repeat study of hereditary predisposition in drug-induced parkinsonism. In: Barbeau A, Brunette JR, eds. Progress

9 Nielsen EB, Lyon M. Evidence for cell loss in corpus striatum after long-term treatment with a neuroleptic drug (flupenthixol) in rats. Psychopharmacology 1978;58:85-9.

10 Goetz CG. Drug-induced parkinsonism and idiopathic Parkinson's disease. Arch Neurol 1983;40:325-6.

11 Figiel GS, Krishnan RR, Doraiswamy M, Nemeroff CB. Caudate hyperintensities in elderly depressed patients with neuroleptic-induced parkinsonism. $f$ Geriatr Psychiatry Neurol 1991;4:86-9.

12 Parkinson study group. DATATOP: a multicenter controlled trial in early Parkinson's disease. Arch Neurol 1989;46:1052-60.

13 Stephen PJ, Williamson J. Drug induced parkinsonism in the elderly. Lancet 1984;10:1082-3.

14 Hausner RS. Neuroleptic induced parkinsonism and Parkinson's disease: differential diagnosis and treatment. $\mathcal{F}$ Clin Psychiatry 1983;44:13-6.

15 Sehti KD, Zamrini EY. Asymmetry in clinical features of drug induced parkinsonism. $\mathcal{f}$ Neuropsychiatry Clin Neurosci 1990;2:64-6.

16 Grafton ST, Sumi SM, Stimac GK, Alvord EC Jr, Shaw CM, Nochlin D. Comparison of postmortem magnetic resonance imaging and neuropathologic findings in the cerebral white matter. Arch Neurol 1991;48:293-8.

17 Kirkpatrick JB, Hayman LA. White matter lesions in MR imaging of clinically healthy brains of elderly subjects: possible pathological basis. Radiology 1988;169:101-4.

18 Thajeb P. Gait disorders of multi-infarct $1988 ; 169: 101-4$. clinical correlation. Acta Neurol Scand 1993;87:239-42.

19 Thompson PD, Marsden CD. Gait disorder of subcortical arteriosclerotic encephalopathy: Binswanger's disease. arteriosclerotic encephal
Mov Disord 1987;2:1-8.

20 Halliwell DS. Oxygen radicals as key mediators in neurological diseases: fact or fiction? Ann Neurol 1992;32: logical 
21 Floyd IA, Carney JM. Free radical damage to protein and DNA: mechanisms involved and relevant observations on brain undergoing oxidative stress. Ann Neurol 1992;32: S22-7.

22 Drayer BP, Olanow W, Burger P, Johnson GA, Herfkens R, Riederer P. Parkinson plus syndrome: diagnosis using high field MR imaging of brain iron. Radiology 1986;159 483-8.

23 Dexter DT, Carayon A, Javoy-Agid F, Agid Y, Wells FR, Daniel SE, et al. Alterations in the levels of iron and ferritin and other trace metals in Parkinson's disease and other neurodegenerative diseases affecting the basal ganglia. Brain 1991;114:1953-75.

24 Ben-Shachar D, Youdim MBH. Neuroleptic induced dopamine receptor supersensitivity and tardive dyskinesia may involve altered brain iron metabolism. $\mathrm{Br} f$ may involve altered

25 Rajan KS, Manian JM, Davis JM, Skripkus A. Studies on the metal chelation of chlorpromazine and its hydroxy- lated metabolites. In: Forrest IS, Carra CJ, Usdin E, eds. The phenothiazines and structurally related drugs. New York: Raven Press 1974.571-91.

26 Casanova MF, Comparini SO, Kim RW, Kleinman JE Staining intensity of brain iron in patients with schizophrenia: a post-mortem study. $\mathcal{F}$ Neuropsychiatry Clin Neurosci 1992;4:36-41.

27 Casanova MF, Waldman IN, Kelinman JE. A post-mortem quantitative study of iron in the globus pallidus of schizophrenic patients. Biol Psychiatry 1990;27:143-9.

28 Campbell WG, Raskind MA, Gordon $\mathrm{T}$, Shaw $\mathrm{CM}$. Iron pigment in the brain of a man with tardive dyskinesia. Am $\mathcal{F}$ Psychiatry 1985;142:364-5.

29 Christensen E, Moller JE. Neuropathological investigation of 28 brains from patients with dyskinesias. Acta Psychiatr of 28 brains from patients with dyskinesias. Acta Psychiat
Scand 1980;46:14-23.

Heinz R, Rayasam K, Krishnan RR, Wingfield M, Irigaray $\mathrm{P}$, Ellinwood EH. MRI scans in patients with tardive dyskinesias. Biol Psychiatry 1988;24:852-60. 